\title{
Top ve çubuk sistemi için kaskad denetleyici parametrelerinin meta-sezgisel algoritmalarla optimizasyonu
}

\section{Optimization of cascade controller parameters for ball and beam system with meta-heuristic algorithms}

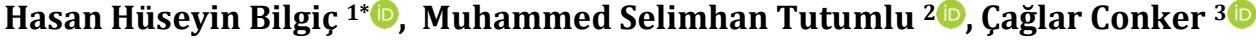 \\ 1,2 İskenderun Teknik Üniversitesi, Mühendislik ve Doğa Bilimleri Fakültesi, Makine Mühendisliği Bölümü, Hatay \\ 3 İskenderun Teknik Üniversitesi, Mühendislik ve Doğa Bilimleri Fakültesi, Mekatronik Mühendisliği Bölümü, Hatay \\ Sorumlu Yazar / Corresponding Author*: hhuseyin.bilgic@iste.edu.tr \\ Geliș Tarihi / Received: 27.04.2020 Araștırma Makalesi/Research Article \\ Kabul Tarihi / Accepted: 06.07.2020 DOI:10.21205/deufmd.2021236714 \\ Atıf sekli/How to cite: BILGIC,, H.H.,TUTUMLU, M.S., CONKER, C..(2021). Top ve çubuk sistemi için kaskad denetleyici parametrelerinin meta- \\ sezgisel algoritmalarla optimizasyonu,DEUFMD, 23(67), 157-167.
}

\section{$\ddot{\mathbf{O z}}$}

Bu çalışmada top ve çubuk sistemi için kaskad PD+P kontrolcü katsayıları meta-sezgisel algoritmalar kullanılarak optimize edilmiștir. Laboratuvar ortamında birçok sistemin benzetiminin elde edilmesini sağlayan top ve çubuk sisteminin amacı çubuk üzerinde tek eksende serbest olarak hareket eden topun referans konuma ulaşması ve dengesinin sağlanmasıdır. Top ve çubuk sistemi hızlı ve yavaş dinamikleri aynı anda içinde barındırdığı için PD+P kaskad kontrolör tasarlanmıştır. Geleneksel kontrolcülere göre ayarlanması zor olan kaskad kontrolcü katsayıları Yapay Arı Kolonisi ve Öğretme Öğrenme Tabanlı Optimizasyon algoritmaları kullanılarak tayin edilmiștir. Uygulanan optimizasyonlarda IAE, ITAE, ISE, MSE amaç fonksiyonları ve yeni bir amaç fonksiyonu olan Birim Basamak Temelli (BB) amaç fonksiyonu önerilmiştir. Önerilen amaç fonksiyonu kullanılarak elde edilen kontrolcü cevaplarında topun istenilen referans konuma hiç aşım yapmadan ulaştığı görülmüştür.

Anahtar Kelimeler: Top ve Cubuk, Kaskad Kontrol, PD+P Kontrol, Meta-sezgisel, Optimizasyon

\begin{abstract}
In this study, cascade $\mathrm{PD}+\mathrm{P}$ controller gains for the ball and beam system are tuned using metaheuristic algorithms. The aim of the ball and beam system, which provides the simulation of many systems in the laboratory environment, is to reach the reference position and balance of the ball, which moves freely on a single axis on the beam. PD+P cascade controller which contained fast and slow dynamics at the same time is designed for the ball and beam system. Cascade controller gains, which are difficult to adjust compared to conventional controllers, are tuned using Artificial Bee Colony and Teaching Learning Based Optimization algorithms. In the optimizations applied, IAE, ITAE, ISE, MSE objective functions, and a new step response based objective function are proposed. In the controller responses obtained using the proposed objective function, the ball reached the desired reference position without overshoot.
\end{abstract}

Keywords: Ball and Beam System, Cascade Control, PD+P Control, Meta-heuristic, Optimization 


\section{Giriş}

Kontrol sistemlerindeki kararlılık seviyesi önemli bir husustur. Modern kontrol sistemlerinin birçoğu kararlılık seviyesini arttırmak için geri besleme kontrol kullanır [1]. Gerçek sistemlerin analizindeki problemlerden en önemlisi çalışılacak sistemin laboratuvar ortamına getirilememesidir. Uçakların inişte ve türbülanslı hava akışı durumlarında yatay dengeyi sağlayabilmek ve benzer konum kontrolü gerektiren problemlere eșdeğer sonuçlar veren top ve çubuk sistemi; dinamik ve kararsız yapısı ile birçok araştırmacının ilgisini çekmektedir [2-4]. İki serbestlik dereceli top ve çubuk sisteminde tanımlanan çubuk üzerinde topun verilen referans konumuna gitmesi ve dengede kalması istenmektedir. Yapılan çalışmalarda dengeyi sağlayabilmek için farklı kontrol sistemleri tasarlanmıştır. PID kontrol denetleyicisi, Yapay Sinir Ağları (YSA) tabanlı denetim sistemleri, Bulanı Mantık Denetleyiciler başlıca kullanılan denetleyicilerdir [5-7]. Model tabanlı kontrolcülerde kararlılı seviyesinin yükseltilmesi için denetleyici kazançlarının seçimi önemli bir husustur. Literatürde kontrolcü kazançlarının optimizasyonu için geleneksel ve meta-sezgisel tabanlı birçok arama algoritması geliștirilmiștir [8-9]. Parçacık Sürü Optimizasyonu (PSO) [10], Yapay Arı Kolonisi (YAK) [11], Yarasa Algoritması Optimizasyonu (YAO) [12], Arı Algoritması (AA) [13] ve Öğretme Öğrenme Tabanlı (ÖÖTO) Optimizasyon [14] bu çalışmalara örnek olarak verilebilir. Geleneksel yöntemlere göre meta-sezgisel algoritmaların daha iyi sonuç verdiği literatürdeki çalıșmalarla kanıtlanmıştır [15-17].

Çalışma kapsamında iki serbestlik dereceli hiyerarşik PD kontrolcü tasarımı yapılmıştır. Literatür çalışmaları incelendiğinde kaskad kontrolcü olarak da adlandırılan hiyerarşik kontrolcülerin oldukça başarılı sonuçlar verdiği ortaya koyulmuştur. Fafmy ve ark., çalışmalarında Arı Algoritması ile robot manipülatörün kontrolünü ele almıșlardır. Ters kinematik analizinin çözümünde Arı Algoritmasını üç MLP’yi (multilayer perceptron) eğitmek için kullanmıșlardır. Ayrıca, esnek uzvun kontrolü için iki aşamalı PID denetleyesinin kazançlarını Arı Algoritması ile optimize etmişlerdir. Çalışmalarının sonucunun literatürdeki birçok çalıșmadan daha iyi sonuç verdiğini ortaya koymușlardır [18]. Abdel-razak ve ark., çalıșmalarında çift sarkaçlı bir tepe vincinin kontrolünü ele almışlardır ve iki farklı kontrol şeması önermişlerdir. Birincisi üç PID kontrolörden oluşan bir yapı ve ikincisi ise iki PD kontrolörden oluşan bir tasarımdır. Denetleyicilerinin kazançlarını beş amaç fonksiyonuna sahip NSGA-II algoritması kullanarak optimize etmişlerdir. Çalışmalarının sonucunda üç PID kontrolörden oluşan tasarımlarının daha başarılı olduğunu ortaya koymuşlardır [19]. Mehedi ve ark., çalışmalarında doğrusal olmayan top ve çubuk sisteminin kontrolü için kesir dereceli kontrol yöntemi önermişlerdir. Servo açısının salınımlarını en aza indirip top konumunun çubuk üzerindeki referans noktasında kalmasını sağlamada tam dereceli kontrol yöntemine olan üstünlüğünü göstermişlerdir [20].

Tınkır ve ark., tek serbestlik dereceli esnek bağlantılı manipülatörün dinamik modelini deneysel olarak belirlenen parametreleri kullanarak CAD yazılımında oluşturmuşlardır. Daha sonra modeli Matlab/Simulink ortamına aktarıp tasarladıkları denetleyicilerini uygulamışlardır. Adaptif yapay siniğ ağı tabanlı bulanık bir kontrolcü kullanarak manipülatörün esnek ucunu istenen konuma taşımada ve kol titreşimlerini ortadan kaldırmakta başarılı olmușlardır. Ayrıca CAD modellerinin sonuçları ile deneysel sonuçlar karşılaştırılıp birbirlerine uyumlu olduğu gözlemlenmiştir. Önerilen yaklaşım sayesinde karmaşık matematiksel denklemlerin türetilmesine gerek kalmadan dinamik modellerin incelenmesi için kullanılabilirliğini göstermişlerdir [21]. Mishra ve ark. yaptıkları çalıșmada DC Motorun hız kontrolünün sağlanabilmesi için PID kontrol kazançlarını Yapay Arı Kolonisi Algoritması ile optimize etmişlerdir. Elde ettikleri bulgular sonucu önerdikleri yöntemin geleneksel yöntemlere göre daha başarılı sonuçlar verdiğini gözlemlemişlerdir [22].

Borah ve ark., doğrusal olmayan açlk döngü kararsızlığına sahip bir top ve plaka sistemi üzerinde çalıșmıșlardır. Topun plaka üzerinde referans konum veya yörüngeyi takip edebilmesi için doğrusallaştırarak Tamsayılı Mertebeden PD (IOPD) ve Kesirli Mertebeden PD (FOPD) kontrolörü tasarlamışlardır. Çalıșmalarında 3 farklı optimizasyon algoritması ile (GSA, FA ve BA) ISE amaç fonskyionunu kullanarak kontrolörlerinin kazanç parametrelerini optimize etmișlerdir. Her iki kontrolörde belirli 
bir yörüngeyi takip edebilmiștir fakat hata minimizasyonu, yörünge takibi ve geçici durum cevaplarının FOPD kontrolörün daha başarılı sonuçlar verdiğini bildirmişlerdir [23].

Roy ve ark., top ve plaka sisteminde topun yörünge kontrolünü sağlamak adına her biri iki döngüden oluşan kademeli Kayan Kipli Kontrol ve Kesirli Mertebeden Kayan Kipli Kontrolör tasarlamıștır. Yaptıkları benzetim ve deneysel çalışmalarda kesir dereceli kayan kipli denetleyicisinin geleneksel kayan kipli kontrolöre göre daha hızlı tepki verdiğini, kalıcı durum hatalarının daha düşük olduğunu ve enerji verimliliğinin daha fazla olduğu sonucuna varmıştır [24].

$\mathrm{Bu}$ çalıșmada top ve çubuk sistemlerinde geleneksel PID kontrolcü yerine iki döngülü bir kaskad kontrolörün daha kararlı çalıştığı gözlemlenmiştir. İç döngü (ikincil döngü) DC motoru, dış döngü (birincil döngü) ise top ve çubuk mekanizmasını kontrol etmektedir. Önerilen yaklașım ile gürültü azaltılarak kontrol döngüsünün dinamik özellikleri geliştirilmiştir. Çalışma kapsamında kontrol cevabının ele alınan sistemin optimum cevabının bulunması için uygun parametrelerin seçimi esastır. Bu seçim geleneksel yöntemlerle çoğu zaman yaklaşık olarak hesaplanabilirken en iyi çözüme ulaşmak mümkün olmayabilmektedir. Bu zorluklardan kaçınmak ve en iyi çözüme kısa sürede ulașabilmek için meta-sezgisel algorimalardan Öğretme Öğrenme Tabanlı Optimizasyon (ÖÖTO) algoritması önerilmiştir. Kaskad PD+P kontrolöre ÖÖTO algoritması uygulanarak sistem kazançları $\left(k_{p 1}, k_{d 1}\right.$ ve $\left.k_{p 2}\right)$ ayarlanmıştır. Maksimum așım, oturma zamanı, kalıcı durum hatası gibi parametrelerde iyileştirmeler sağlanmıştır ve elde edilen sonuçlar Yapay Arı Algoritması sonuçları ile karşılaşmıştır.

\section{Top ve Cubuk Sisteminin Matematiksel Modeli}

Top ve çubuk sistemi; bir uçağın iniş-çıkışı sırasında ve türbülanslı hava akışında yatay olarak dengelenmesi, helikopterlerin yatay dengeleme benzetimi, hareketli robot tarafından yük tașımada sırasındaki denge problemi vb. kontrol problemlerine laboratuvar ortaminda yaklaşımda bulunmayı sağlar. Top ve çubuk sisteminde amaç; çubuk üzerindeki topu dengelemektir. Top ve Çubuk sitemi iki serbestlik derecesine sahiptir ve Sekil 1'de top üzerine etki eden kuvvetler ile birlikte gösterilmiștir. Serbestlik derecelerinden biri çubuğun üzerindeki topun pozisyonu, diğeri ise çubuğun yatay düzlem ile yaptığı açısal pozisyondur.

Kaldıraç kolu ile mafsallanmış çubuğun eğimi $(\alpha)$, motorun pozisyon açısının $(\theta)$ değişmesine bağlı olarak yukarı ve aşağı hareket eder.

Uygulanan kontrol sisteminin amacl, topun pozisyonunun istenilen konuma getirilmesi ve referans konumda dengede kalabilmesini sağlamak için servo motora uygun voltaj verilerek çubuğun açısının ayarlanmasıdır.

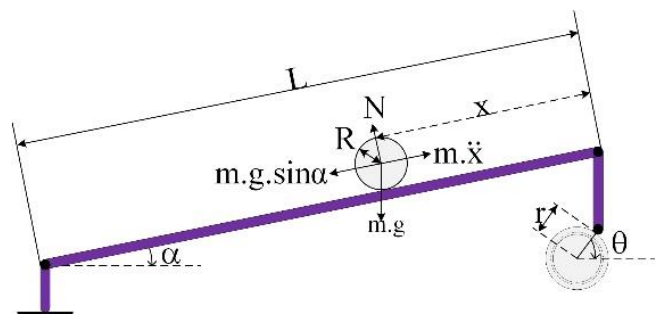

Şekil 1. Top ve Çubuk Sistemi Serbest Cisim Diyagramı

Newton'un ikinci hareket yasası kullanılarak sistemin hareket denklemleri elde edilir. Top ve çubuk sistemine ait elde edilen denklemler kullanılarak sistemin transfer fonksiyonu olușturulur. Topun ve çubuğun dinamiklerini tanımlayan transfer fonksiyonu aşağıdaki şekilde elde edilebilir. Çubuk üzerindeki topa etki eden kuvvetlerden biri yerçekiminden kaynaklanan ağırlık vektörünün bileşeni olan doğrusal kuvvettir $\left(F_{t x}\right)$. Bir diğeri, topun dönme ivmesi ile üretilen torktan kaynaklanan bir dönme kuvvetidir $\left(F_{r x}\right)$. Bu iki kuvvet Eşitlik 1 ve 3 ile ifade edilebilir.

$F_{t x}=m g \sin \alpha$

Topun dönme hareketi tarafından üretilen tork, topun hareket yönüne zıt olan dönme kuvveti ile topun yarıçapının çarpımına eşittir. Newton'un ikinci hareket denklemini kullanarak torkun, topun atalet momentinin açısal ivmesiyle çarpımına eşit olduğu bilinmektedir.

Ayrıca topun doğrusal hareketinin çift türevi ile çarpılan atalet momentinin yarıçapa bölümü bize yine torku verecektir.

$J=(2 / 5) m R^{2}$

$T_{r}=F_{r x} R=J a=J(\ddot{x} / R)$ 
Dönme kuvvetini elde edebilmek için topun atalet momentinini kullanarak denklemde düzenlemeler yapılır ve aşağıdaki ifade üretilir.

$F_{r x}=\frac{2}{5} m \ddot{x}$

Newton'un ikinci hareket yasası kullanılarak aşağıdaki denklem elde edilir.

$m \ddot{x}=\sum F=F_{t x}-F_{r x}=m g \sin \alpha-\left(\frac{2}{5}\right) m \ddot{x}$

Denklem 5'in yeniden düzenlenmesi ile aşağıdaki ifade elde edilir.

$\ddot{x}=\frac{5}{7} g \sin \alpha$

Denklem 6'da sin $\alpha^{\prime}$ nın çok küçük değerleri için doğrusallaştırma yapılır.

$\frac{X(s)}{\alpha(s)}=\frac{5 g}{7 s^{2}}$

Daha sonra motor gerilimi $\left(V_{m}\right)$ ve çıkış açısı $(\theta)$ tarafından üretilen transfer fonksiyonu aşağıdaki șekilde ifade edilir [25]:

$\frac{\theta(s)}{V_{m}(s)}=\frac{K}{\tau s^{2}+s} \frac{\theta(s)}{V_{m}(s)}=\frac{1.53}{0.0248 s^{2}+s}$

Servo motorun açısal pozisyonu $(\theta)$ ile çubuk açısal pozisyonu $(\alpha)$ arasındaki ilişki Denklem 9 da verilmiştir.

$\theta r=L \alpha$

Ayrıca denklem(9) aşağıdaki gibi düzenlenebilir.

$\theta=\frac{L}{r} \alpha$

Sonunda așağıdaki transfer fonksiyonu elde edilir.

$\frac{\alpha(S)}{\theta(S)}=\frac{r}{L}$
Bir durum geri besleme denetleyicisi, açlk döngü transfer fonksiyonu formuna dayanarak tasarlanabilir.

$\frac{X(s)}{V_{m}(s)}=\frac{\theta(s) \alpha(s) X(s)}{V_{m}(s) \theta(s) \alpha(s)}$

Tablo.1. Top ve Çubuk özellikleri

\begin{tabular}{lll}
\hline Sembol & Açılkama & Değer \\
\hline$L$ & Çubuk uzunluğu & $42.55 \mathrm{~cm}$ \\
$m$ & Top kütlesi & $0.064 \mathrm{~kg}$ \\
$R$ & Top yarıçap uzunluğu & $1.27 \mathrm{~cm}$ \\
$r$ & Motor şaftı ve kaldıraç & $2.54 \mathrm{~cm}$ \\
& kolu arasındaki eklem & \\
$g$ & uzunluğu & \\
\hline
\end{tabular}

\section{PD+P Kaskad Kontrolör Tasarımı}

Kaskad kontrol sistemleri iki kontrol döngüsü tarafından oluşturulur. Giriş bozulmalarını ortadan kaldırmak için hızlı dinamiğe sahip bir iç döngü ve çıkış performansını düzenlemek için bir dıș döngü. Geleneksel olarak, sıralı bir şekilde ayarlanırlar. İlk olarak, dış döngü denetleyicisi manuel olarak ayarlanır. Daha sonra, iç döngü kontrolörü devreye alınır ve ayarlama işlemini tamamlamak için diş döngü kontrol cihazı ayarlanır. Elde edilen kontrol performansı tatmin edici değilse, tüm sekans tekrarlanmalıdır. Bu nedenle, özellikle yüksek zaman sabiti ve zaman gecikmesi olan sistemler için kademeli bir kontrol sistemini ayarlamak oldukça zahmetli ve zaman alıcı bir iştir.

Geleneksel PD+P kaskad kontrolör mimarisi Şekil 2'de sunulmaktadır. Kaskad kontrolör yapısının avantajları, ilk kontrol ünitesi performansı sınırlayan önemli derecede kararsızlıklar içerdiğinde ortaya çıkar. Ayrıca, Kaskad kontrolörü, gürültüyü hafifletip gürbüzlük sağlayarak kontrol döngüsünün dinamik özelliğini geliştirir.

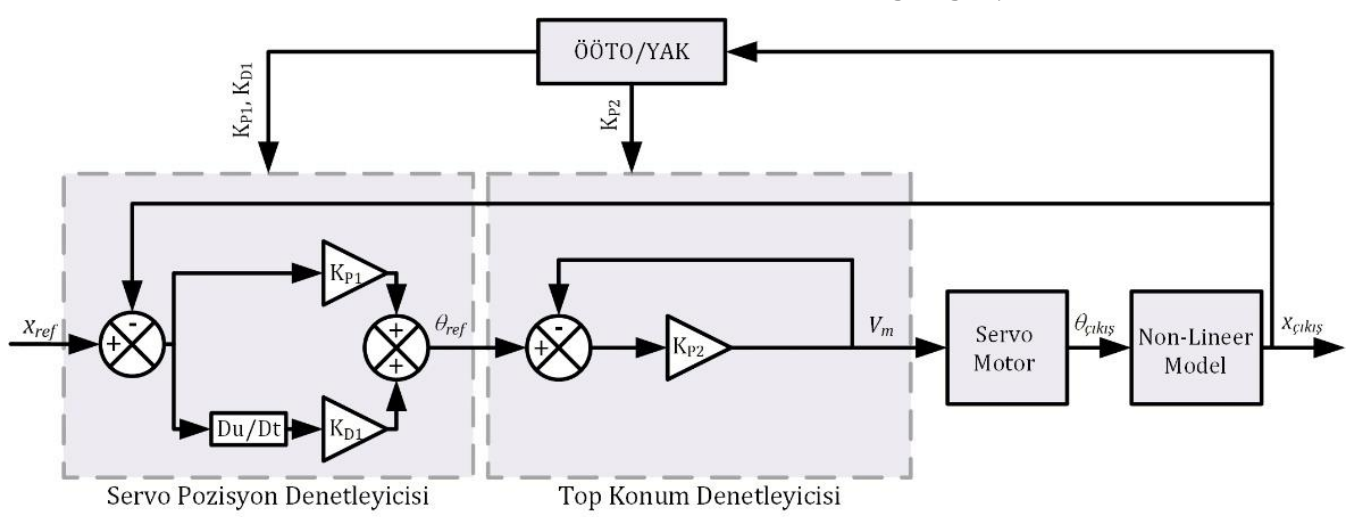

Şekil 2. PD+P Kaskad Kontrol Mimarisi 


\section{PD+P Katsayılarının Optimizasyonu}

\section{1. Öğretme Öğrenme Tabanlı Optimizasyon (ÖÖTO) Algoritması}

Öğretme Öğrenme Tabanlı Optimizasyon (ÖÖTO) algoritması popülasyona dayalı bir optimizasyon tekniğidir. Popülasyon olarak bir grup veya sınıf öğrenen ele alınır ve bilgi düzeyi en yüksek kişi olan bir öğretmen belirlenir. Öğretmen sınıfdaki öğrencileri kendi bilgi düzeyine yaklaştırmaya çalışır. Öğretmenin performansını sınıfdaki öğrenenlerin aldığı sonuçların ortalaması belirlemektedir. ÖÖTO algoritması öğretmen ve öğrenen fazı olmak üzere iki bölüme ayrılmıștır. Öğretmen fazı popülasyondaki bilgi düzeyi en yüksek olan kişi öğretmen olarak seçilir ve sınıfın bilgi düzeyini kendi seviyesine yaklaștırmaya çalıșır. Öğrenci Fazı ise öğretmenden bağımsız olarak öğrenenlerin kendi aralarındaki etkileșimden faydalanarak bilgi düzeyini arttırmalarıdır [26].

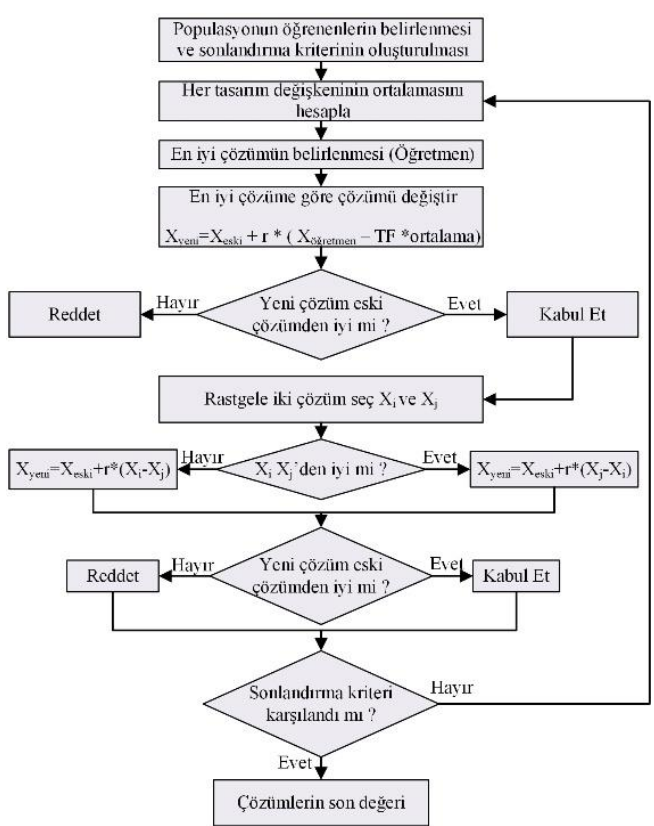

Şekil.3. ÖÖTO Akış Diyagramı

ÖÖTO algoritması akış diyagramındaki öğretim sürecine dayanarak, sınırlandırılmamış doğrusal olmayan bir sürekli fonksiyonun optimizasyonu için matematiksel bir model hazırlanır ve uygulanır, böylece ÖÖTO algoritması adı verilen yeni bir optimizasyon tekniği geliştirilir. Şekil 3'de ÖÖTO algoritmasının program akış șeması gösterilmektedir.

\subsection{Yapay Arı Kolonisi (YAK) Algoritması}

Yapay Arı Kolonisi Algoritması çok değișkenli fonksiyonların optimize edilmesinde kullanılan meta-sezgisel bir algoritmadır [27]. Temelde bal arısı sürüsünün yiyecek bulmak için akıllıca ve organize davranışlarına dayanır. Yapay arı kolonisi toplamda üç farklı arı grubundan oluşmaktadır. Üç grup sırası ile işçi arılar, gözcü arılar ve kaşif arılar olarak adlandırılır. Modelde koloninin yarısı işçi arı olarak seçilmiștir ve kalan yarısı gözcü arı olarak belirlenmiştir. Her bir nektar kaynağı için sadece bir işçi arı bulunmaktadır ve işçi arıların sayısı nektar kaynağına eşittir. Yiyecek kaynakları optimize edilmeye çalışılan top ve çubuk sisteminin kaskad PD+P kazanç parametreleridir. Bir kaynağa ait nektar miktarı, o kaynakla ifade edilen çözümün kalite değerini göstermektedir.

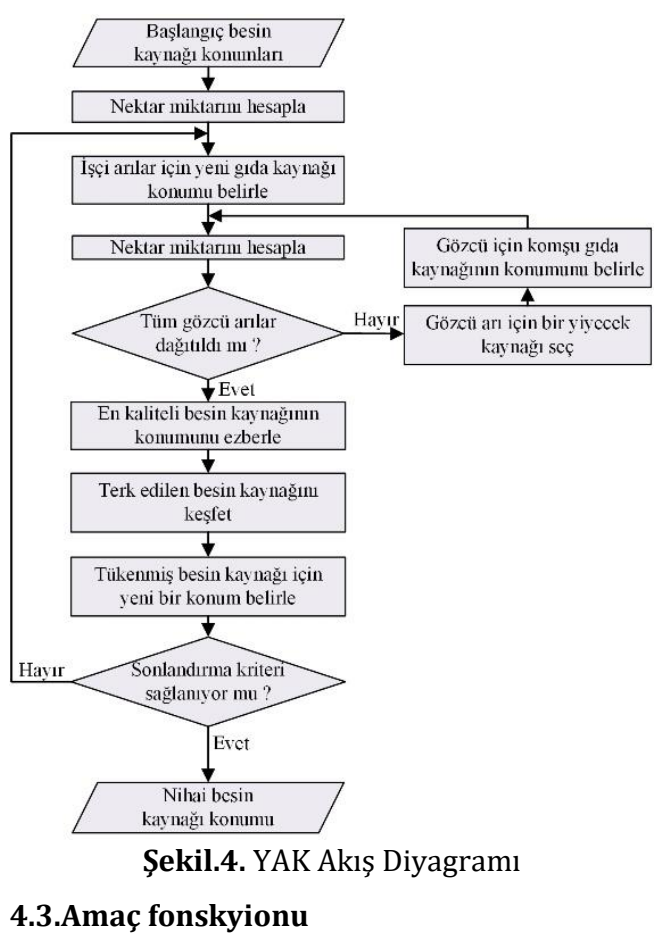

Çalıșma kapsamında literatürde etkinliği kanıtlanmış IAE, ISE, ITAE ve MSE amaç fonksiyonlarının her biri ayrı olarak kullanılmıștır. Ayrıca, sistem cevabını iyileştirmek için Birim Basamak (BB) cevabı temelli bir amaç fonksiyonu tanımlanmıștır. Makalede kullanılan amaç fonksiyonlarının ve matematiksel modellerinin her biri Denklem 1317 'de gösterilmektedir. Sunulan çalıșma 
kapsamında kullanılan amaç fonksiyonları için aynı populasyon sayılarında 50 iterasyon için optimizasyon yapılmıştır.

$$
\begin{aligned}
& B B=t_{r}+t_{s}+t_{p}+50 M_{p}+100 e_{s s} \\
& I A E=\int_{0}^{t}|e(t)| d t \\
& I S E=\int_{0}^{t} e^{2}(t) d t \\
& I T A E=\int_{0}^{t} t|e(t)| d t \\
& M S E=\frac{1}{N} \sum_{k=1}^{N} e^{2}(k)
\end{aligned}
$$

Denklem 13'de; $t_{r}, t_{p}, t_{s}, M_{p}$, ve $e_{s s}$ sirasiyla yükselme zamanı, pik zamanı, yerleșme zamanı, azami aşma ve kalıcı durum hatasıdır.

\section{Araştırma Bulguları}

\section{1. ÖÖTO Algoritması ile Optimizasyon}

Uygulanan optimizasyonda ÖÖTO algoritması için aynı parametreler ile ve iterasyon sayısıyla 5 farklı amaç fonksiyonu ile arama yapılmıștır.

Kullanılan parametreler; itarasyon sayısı 20 ve maksimum itarasyon sayısı 2400 olarak belirlenmiștir. Ayrıca kaskad kontrolörün iç ve dış döngülerinde $k_{p 1}, k_{d 1}, k_{p 2}$ sınırları sırası ile 45 ,
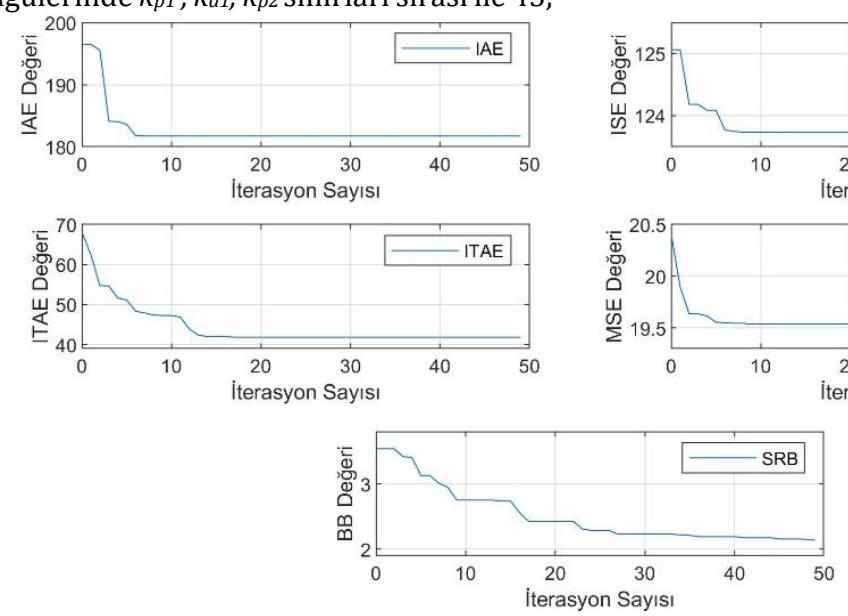

Şekil.5. ÖÖTO Algoritması için yakınsama grafikleri
15, 25 olarak sınırlandırılmıștır. Literatürde sıklıkla kullanılan ISE, IAE, ITAE, MSE ve BB amaç fonksiyonları yinelenen iterasyon sayısı ile birlikte minimum değere yaklaştıkları görülmektedir.

Şekil 5 incelendiği takdirde MSE'yi takiben ISE amaç fonksiyonunun mümkün olan en kısa süre içerisinde global en iyi seviyeye ulaştığ görülmektedir. İterasyon sayısına göre değișen uygunluk değerindeki en yüksek fark ise ISE amaç fonksiyonunda görülmektedir ve bunu ITAE amaç fonksiyonu takip etmektedir.

Uygulanan optimizasyon sonucu elde edilen kontrol parametreleri top ve çubuk sisteminde kullanılıp elde edilen sistem cevapları Şekil 6'da gösterilmiştir. Grafikler incelendiğinde önerilen BB amaç fonksiyonun aşma yapmadığını ve yükselme süresinin 0.753 sn gibi düşük bir değer olduğu görülmektedir. Her amaç fonksiyonu için elde edilen parametrelerle PD+P kontrolör ayarlanmıștır. Tablo 2'de kullanılan amaç fonksiyonları için PD+P kazançları, yükselme zamanı, oturma zamanı, aşım zamanı, azami aşma, kalıcı durum hatası ve optimizasyon süresi detaylı olarak gösterilmiştir.
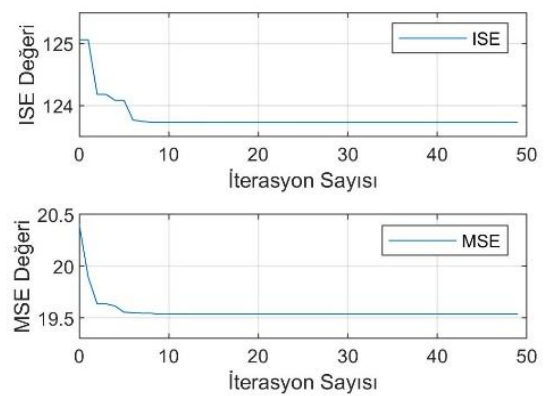


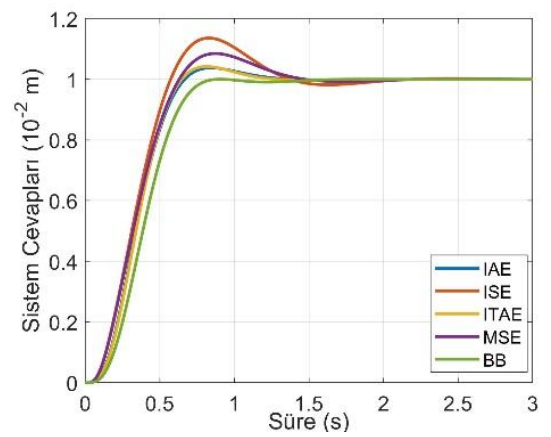

Şekil.6.a) Sistem Cevapları

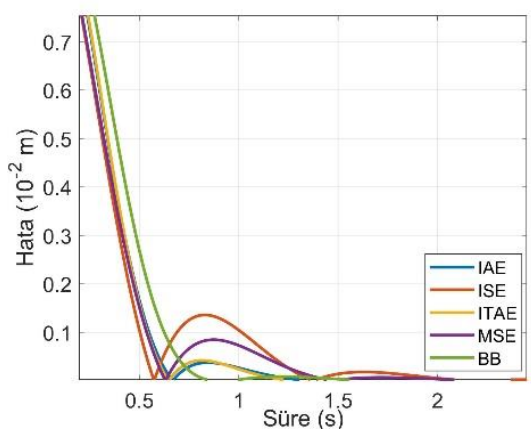

Şekil.6.b) Mutlak Sistem Hatası

Tablo.2. PID kazançları, adım yanıtları ve optimizasyon süreleri

\begin{tabular}{|c|c|c|c|c|c|c|c|c|c|}
\hline \multirow{2}{*}{$\begin{array}{l}\text { Amaç } \\
\text { Fonksiyonu }\end{array}$} & \multicolumn{2}{|c|}{ PD } & \multirow{2}{*}{$\begin{array}{r}\mathrm{P} \\
\boldsymbol{k}_{p 2}\end{array}$} & \multicolumn{5}{|c|}{ Sistem Cevapları } & \multirow{2}{*}{$\begin{array}{l}\text { Optimizasyo } \\
\text { n Süresi (s) }\end{array}$} \\
\hline & $k_{p 1}$ & $k_{d 1}$ & & $t_{r}(s)$ & $t_{s}(s)$ & $t_{p}(s)$ & $M_{p}(s)$ & $e_{s s}$ & \\
\hline$B B$ & 37.19 & 14.95 & 7.228 & 0.432 & 0.753 & 0.906 & 1.000 & - & 273 \\
\hline$I A E$ & 45 & 15 & 10.04 & 0.381 & 1.062 & 0.844 & 1.037 & - & 275 \\
\hline ISE & 45 & 11.58 & 25 & 0.364 & 1.275 & 0.830 & 1.136 & - & 273 \\
\hline ITAE & 45 & 15 & 9.211 & 0.370 & 1.032 & 0.814 & 1.042 & - & 268 \\
\hline$M S E$ & 45 & 13.07 & 22.74 & 0.396 & 1.291 & 0.874 & 1.084 & - & 282 \\
\hline
\end{tabular}

Tablo 2 incelendiği takdirde amaç fonksiyonları fonksiyonlarında en düşük ve en yüksek değer içerisinde maksimum așımın en düșük olduğu amaç fonksiyonunun önerilen BB fonksiyonu olduğu görülmektedir.

Ayrıca kalıcı duruma ulașma süresi 0.753 sn olan fonksiyon da yine BB fonskiyonu olduğu görülmektedir. Yükselme zamanı açısından tüm fonksiyonlar benzer sonuç vermektedir.

\subsection{YAK Algoritması ile Optimizasyon}

Şekil 7'de farklı amaç fonksiyonlarının iterasyon sayısına göre değişimlerinde en hızlı minimum değere ulaşan fonksiyonun IAE olduğu görülmektedir. BB amaç fonksiyonu ise daha fazla iterasyon sayısında minimum değere yaklaştığı gözlemlenmiștir.

Amaç arasındaki fark en fazla IAE fonksiyonunda gözlemlenmiştir. En düşük fark ise BB ve MSE de olduğu görülmektedir.

Sistem cevapları incelenildiğinde ise ; yükselme zamanları arasında minimal farklar görülmektedir, kalıcl durum hatası bulunmamakta olup kalıcı duruma geçiş sürelerinde ise 0.753 sn ile $\mathrm{BB}$ ve onu takiben 1.062 sn ile IAE ve 1.032 sn ile ITAE fonksiyonları olduğu görülmektedir. En yüksek aşma ise yüzde 10 aşım ile ISE fonksiyonunda gözlemlenmiştir. Önerilen amaç fonksiyonu BB ise verilen referans değerine aşma oluşturmadan ulaştığı görülmektedir. 
DEÜ FMD 23(67), 157-167, 2021
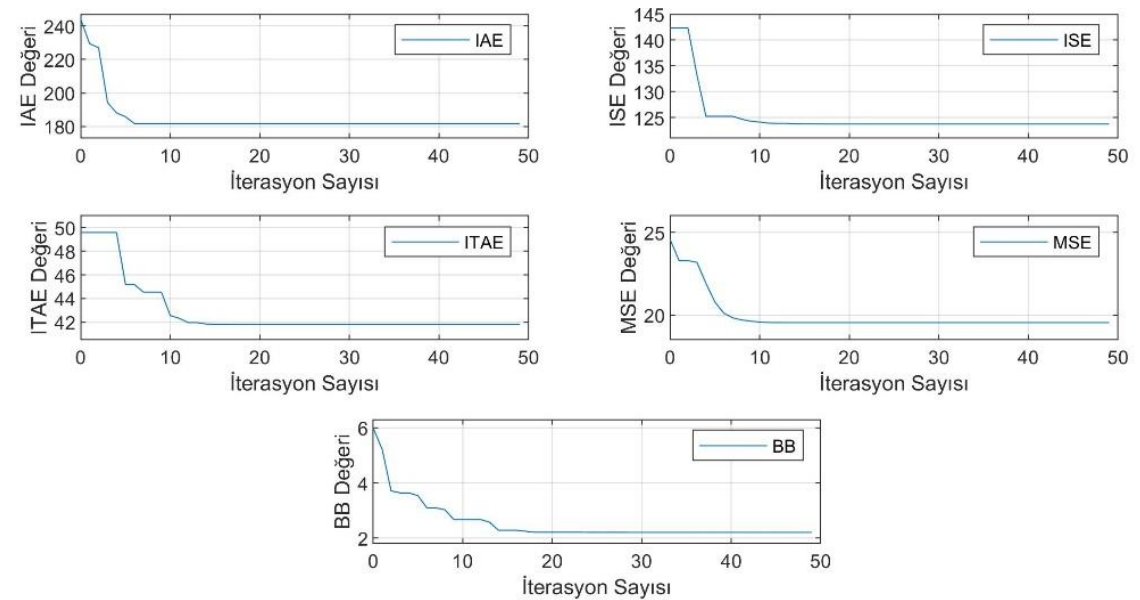

Şekil.7 YAK Algoritması için yakınsama grafikleri

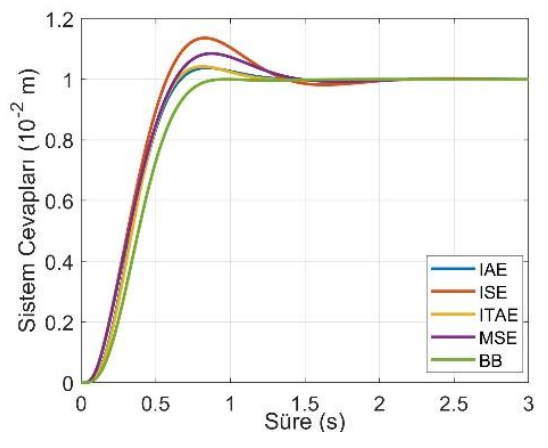

Şekil.8.a) Sistem Cevapları

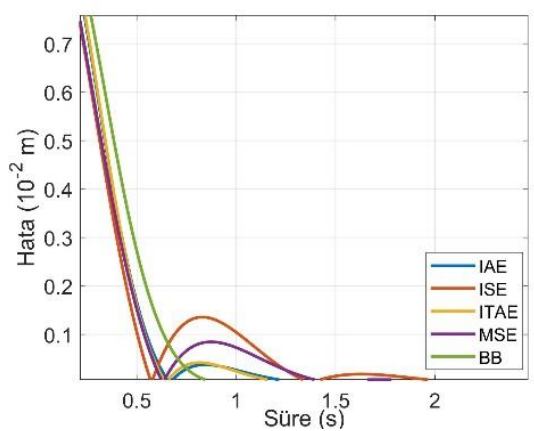

Şekil.8.b) Mutlak Sistem Hatası

Tablo.3 PID kazançları, adım yanıtları ve yöntemlerin optimizasyon zamanları

\begin{tabular}{|c|c|c|c|c|c|c|c|c|c|}
\hline \multirow{2}{*}{$\begin{array}{l}\text { Amaç } \\
\text { Fonksiyonu }\end{array}$} & \multicolumn{2}{|c|}{ PD } & \multicolumn{2}{|l|}{$\mathrm{P}$} & \multicolumn{3}{|c|}{ Sistem Cevapları } & \multirow[b]{2}{*}{$e_{s s}$} & \multirow{2}{*}{$\begin{array}{l}\text { Optimizasyon } \\
\text { Süresi (s) }\end{array}$} \\
\hline & $k_{p 1}$ & $k_{d 1}$ & $k_{p 2}$ & $t_{r}(s)$ & $t_{s}(s)$ & $t_{p}(s)$ & $M_{p}(s)$ & & \\
\hline$B B$ & 36.99 & 14.82 & 7.813 & 0.445 & 0.780 & 0.972 & 1.000 & - & 301 \\
\hline$I A E$ & 45 & 15 & 10.04 & 0.381 & 1.062 & 0.844 & 1.037 & - & 285 \\
\hline$I S E$ & 45 & 11.58 & 25 & 0.364 & 1.275 & 0.830 & 1.136 & - & 288 \\
\hline ITAE & 45 & 15 & 9.211 & 0.370 & 1.032 & 0.814 & 1.042 & - & 312 \\
\hline MSE & 45 & 13.07 & 22.74 & 0.396 & 1.291 & 0.874 & 1.084 & - & 311 \\
\hline
\end{tabular}

Tablo 3'de görüldügü üzere en başarılı sonuç önerilen amaç fonksiyonu ile elde edilmiştir. Literatürdeki amaç fonksiyonları ile karşılaştırıldığında en büyük farkın maksimum aşım noktasında ve oturma zamanına $0.780 \mathrm{sn}$ gibi düşük değerde ulaşması olarak nitelendirilebilir. 
DEÜ FMD 23(67), 157-167, 2021

\section{6. ÖÖTO ve YAK Algoritmalarının Karşılaștırılması}

Optimizasyon algoritmalarının performansları tasarım değişkenlerinin alt ve üst limitleri ile amaç fonksiyonları dikkate alınarak karşılaştırılmıştır. Tasarım değişkenlerinin üst limitleri $k_{p 1}, k_{d 1}, k_{p 2}$ sırası ile 451525 olarak ayarlanmıștır. Popülasyon 20 ve maksimum iterasyon sayısı, 2400, olacak şekilde her iki iterasyon için de aynı seçimle optimizasyon yapılmıştır. $\mathrm{Bu}$ makalede önerilen Birim Basamak (BB) cevap temelli amaç fonksiyonunun iterasyon sayısına göre değișimi her iki optimizasyon algoritması için global çözüme olan yaklaşımları görülmektedir. Şekil 5 ve Şekil 7 incelendiğinde ÖÖTO algoritması daha düșük bir uygunluk değeri verirken YAK algoritmasının ise en düşük uygunluk değerine

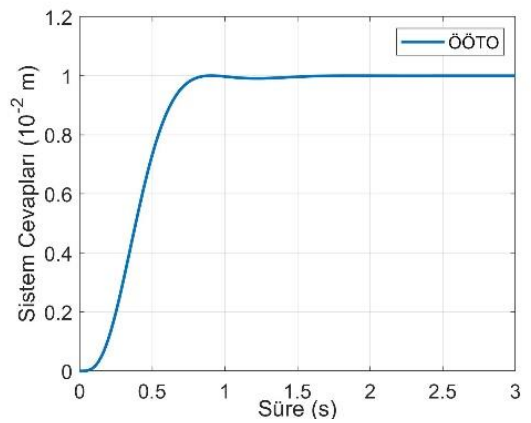

Şekil.8.a) ÖÖTO için Sistem Cevabı

\section{Sonuç}

$\mathrm{Bu}$ çalışmada top ve çubuk sisteminde hassas konum kontrolü sağlayabilmek için kapalı çevrim PD+P kaskad kontrol kazanç parametreleri optimize edilmiștir. Yapılan optimizasyon işleminde alışılagelmiş metasezgisel yöntemlerden farklı olarak ÖÖTO algoritması kullanılmıştır ve YAK algoritması ile karşılaştırılmıştır. Temelde iki fazdan oluşan algoritma, Öğretmen ve Öğrenci fazları ile global çözüme ulaşmaktadır. Literatürde sıklıkla kullanılan dört amaç fonskyionu ve çalışmada önerilen BB amaç fonksiyonu önerilmiştir. Yenilik olarak önerilen BB amaç fonksiyonunun diğer amaç fonksiyonlarından daha etkin olduğu sonucuna varılmıştır. Ayrıca Öğretme Öğrenme Tabanlı Optimizasyon algoritması Yapay Arı Kolonisi algoritması ile karşılaştırılmıștır ve iki algoritma içinde yapılan iyileştirmelerin etkinliği kanıtlanmıștır. ulaşması daha düşük iterasyon sayılarında sağlandığı görülmüştür.

Bu makalede önerilen BB amaç fonksiyonunun uygunluk değerinin değişimleri incelendiği takdirde ÖÖTO algoritmasında daha düşük bir uygunluk değeri ile başladığı görülmektedir. Literatürdeki amaç fonksiyonları için uygunluk değerlerinin değişimi benzer olmakla birlikte ÖÖTO algoritmasının optimizasyon süreci bir miktar daha kısa sürmüştür.

Her iki optimizasyon algoritması için elde kontrol parametrelerinin top ve çubuk sistemine uygulandığı durumda elde edilen sistem cevapları Șekil 8'de karşılaștırılmıștır ve benzer sonuçlar verdiği gözlemlenmiştir. Aynı durum MSE, ISE, ITAE, IAE amaç fonksiyonları içinde geçerliliğini korumaktadır.

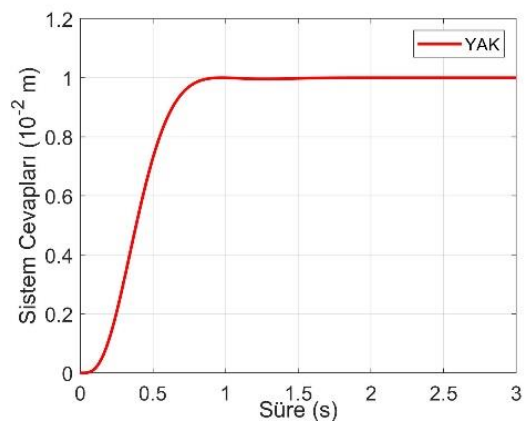

Şekil.8.b) YAK için Sistem Cevab

Sonuç olarak BB, MSE, ISE, ITAE ve IAE amaç fonksiyonlarının top ve çubuk sisteminde topun bozuculara karşı referans konum noktasına hızlı ve kararlı bir şekilde ulaştığı gözlemlenmiştir. Ayrıca bu çalışmada incelenen ÖÖTO algoritması ve amaç fonksiyonlarının benzer konum kontrol problemlerinde çözüm sağlaması için altyapı oluşturmuştur.

ÖÖTO algoritmasında ayarlanması gereken tasarım değișkeni sayısı sadece öğrenci sayısıdır Arl algoritmasındanda ise arl sayısı, modifikasyon oranı, vazgeçme için önceden belirlenmiş deneme sayısı gibi parametrelerin ayrıca ayarlanması gerekmektedir. Her iki algoritmada benzer sonuçlar vermesine rağmen optimizasyon sürecinin daha kısa sürmesi ve ayarlanması gereken parametrelerin daha düşük olması sebebiyle ÖÖTO algoritması daha avantajlı olduğu sonucuna ulaşılmıştır. 
DEÜ FMD 23(67), 157-167, 2021

\section{Kaynakça}

[1] Conker, C., \& Karaca, A. (2019). Bulanık Mantık Esash Karar Destek Sistemi ile Robot Elin Kuvvet Kontrolünün Sağlanması.Dokuz Eylül Üniversitesi Mühendislik Fakültesi Fen ve Mühendislik Dergisi, 21(62), 433-447.

[2] Kim, J. S., Park, G. M., \& Choi, H. L. (2010, October) Sliding mode control design under partial state feedback for ball and beam system. In ICCAS 2010 (pp. 1293-1296). IEEE.

[3] Azar, A. T., Ali, N., Makarem, S., Diab, M. K., \& Ammar H. H. (2019, October). Design and Implementation of a Ball and Beam PID Control System Based on Metaheuristic Techniques. In International Conference on Advanced Intelligent Systems and Informatics (pp. 313-325). Springer, Cham.

[4] Borah, M., Majhi, L., Roy, P., \& Roy, B. K. (2014). Design of a fractional order pd controller tuned by firefly algorithm for stability control of the nonlinear ball and plate system. In IEEE International Conference on Advanced Communication Control and Computing Technologies, Ramanathapuram, India.

[5] Coban, S., Bilgic, H. H., \& Akan, E. (2020). Improving Autonomous Performance of a Passive Morphing Fixed Wing UAV. Information Technology and Control, 49(1), 28-35.

[6] Castillo, O., Lizárraga, E., Soria, J., Melin, P., \& Valdez, F. (2015). New approach using ant colony optimization with ant set partition for fuzzy control design applied to the ball and beam system. Information Sciences, 294, 203-215.

[7] Chang, Y. H., Chang, C. W., Tao, C. W., Lin, H. W., \& Taur, J. S. (2012). Fuzzy sliding-mode control for ball and beam system with fuzzy ant colony optimization. Expert Systems with Applications, 39(3), 3624-3633.

[8] Bilgic, H. H., Sen, M. A., \& Kalyoncu, M. (2016). Tuning of LQR controller for an experimental inverted pendulum system based on The Bees Algorithm. Journal of Vibroengineering, 18(6), 36843694.

[9] Arif Şen, M., Tinkir, M., \& Kalyoncu, M. (2018) Optimisation of a PID controller for a two-floor structure under earthquake excitation based on the bees algorithm. Journal of Low Frequency Noise, Vibration and Active Control, 37(1), 107-127.

[10]Özkop, E., \& Altas, İ. H. Buhar Generatörünün Su Seviyesi Denetimi Için Pso Temelli Klasik Ve Akilli Denetleyicilerin Performansi. Dokuz Eylül Üniversitesi Mühendislik Fakültesi Fen ve Mühendislik Dergisi, 19(57), 835-844.

[11]Erkol, H. O. (2017). Ters sarkaç sisteminin yapay arı kolonisi algoritması ile optimizasyonu. Politeknik Dergisi, 20(4), 863-868.

[12]Eke, İ., \& Temel, B. Yarasa Algoritması Kullanılarak Tek Makinalı Sonsuz Baralı Güç Sisteminin, Geleneksel ve PID Güç Sistem Dengeleyicisi (GSD) Parametrelerinin Belirlenmesi. Uluslararası Mühendislik Araştırma ve Geliştirme Dergisi, 12(1), 278-291.

[13]Șen, M. A., Bilgiç, H. H., \& Kalyoncu, M. (2016). Cift Ters Sarkaç Sisteminin Denge Ve Konum Kontrolü İçin Ari Algoritmasi İle Lqr Kontrolcü Parametrelerinin Tayini. Mühendis ve Makina, 57(679), 53-62.

[14] Mishra, A., Singh, N., \& Yadav, S. (2020). Design of Optimal PID Controller for Varied System Using Teaching-Learning-Based Optimization. In Advances in Computing and Intelligent Systems (pp. 153-163). Springer, Singapore.

[15] Mahmoodabadi, M. J., \& Rezaee Babak, N. (2020). Fuzzy adaptive robust proportional-integralderivative control optimized by the multi-objective grasshopper optimization algorithm for a nonlinear quadrotor.Journal of Vibration and Control, 1077546319901019.

[16] Mahmoodabadi, M. J., \& Nejadkourki, N. (2020). Optimal fuzzy adaptive robust PID control for an active suspension system. Australian Journal of Mechanical Engineering, 1-11.

[17] Gani, A., Özçalık, H. R., Açıkgöz, H., Keçecioğlu, Ö. F., \& Kılıç, E. (2014). Farklı Kural Tabanları Kullanarak PIBulanık Mantık Denetleyici ile Doğru Akım Motorunun $\mathrm{Hiz}$ Denetim Performansının İncelenmesi. Akademik Platform Mühendislik ve Fen Bilimleri Dergisi, 2(1), 16-23.

[18]Fahmy, A. A., Kalyoncu, M., \& Castellani, M. (2012). Automatic design of control systems for robot manipulators using the bees algorithm. Proceedings of the Institution of Mechanical Engineers, Part I: Journal of Systems and Control Engineering, 226(4), 497-508.

[19] Abdel-razak, M. H., Ata, A. A., Mohamed, K. T., \& Haraz, E. H. (2020). Proportional-integral-derivative controller with inlet derivative filter fine-tuning of a double-pendulum gantry crane system by a multiobjective genetic algorithm. Engineering optimization, 52(3), 527-548.

[20] Mehedi, I. M., Al-Saggaf, U. M., Mansouri, R., \& Bettayeb, M. (2019). Two degrees of freedom fractional controller design: Application to the ball and beam system. Measurement, 135, 13-22.

[21] Tinkir, M., Önen, Ü., \& Kalyoncu, M. (2010). Modelling of neurofuzzy control of a flexible link. Proceedings of the Institution of Mechanical Engineers, Part I: Journal of Systems and Control Engineering, 224(5), 529-543.

[22] Mishra, A. K., Tiwari, V. K., Kumar, R., \& Verma, T. (2013, December). Speed control of DC motor using artificial bee colony optimization technique. In 2013 International Conference on Control, Automation, Robotics and Embedded Systems (CARE) (pp. 1-6). IEEE.

[23]Borah, M., Roy, P., \& Roy, B. K. (2018). Enhanced performance in trajectory tracking of a ball and plate 
DEÜ FMD 23(67), 157-167, 2021

system using fractional order controller. IETE Journal of Research, 64(1), 76-86.

[24]Roy, P., Das, A., \& Roy, B. K. (2018). Cascaded fractional order sliding mode control for trajectory control of a ball and plate system. Transactions of the Institute of Measurement and Control, 40(3), 701-711.

[25] Quanser, Ball and beam user manuals, 2008.

[26] Rao, R. V., Savsani, V. J., \& Vakharia, D. P. (2011) Teaching-learning-based optimization: a novel method for constrained mechanical design optimization problems. Computer-Aided Design, 43(3), 303-315.

[27] Karaboga, D., \& Basturk, B. (2007). A powerful and efficient algorithm for numerical function optimization: artificial bee colony (ABC) algorithm. Journal of global optimization, 39(3), 459-471. 